09

\title{
Особенности спектральных характеристик узкополосных светофильтров при наклонном падении пучка излучения
}

\author{
(C) V.B. Nguyen ${ }^{1}$, Л.A. Губанова ${ }^{1}$, D.B. Bui ${ }^{2}$ \\ ${ }^{1}$ Санкт-Петербургский национальный исследовательский университет информационных технологий, \\ механики и оптики (Университет ИТМО), Санкт-Петербург, Россия \\ ${ }^{2}$ Le Quy Don Technical University, Hanoi, Vietnam \\ E-mail: thulavang@gmail.com
}

Поступило в Редакцию 4 декабря 2018г.

В окончательной редакции 4 декабря 2018г.

Принято к публикации 8 февраля 2019г.

Работа узкополосных светофильтров на основе нарушенного полного внутреннего отражения проанализирована с учетом гауссовского распределения угла падения излучения. Спектральные характеристики данных светофильтров смоделированы при наличии расходимости падающего пучка и без нее. Показано, что при измерении спектральных характеристик светофильтров расходимость падающего пучка излучения не должна быть больше некого предельного значения, которое не превышает несколько угловых минут.

DOI: 10.21883/PJTF.2019.09.47704.17620

Узкополосные светофильтры, работа которых основывается на явлении нарушенного полного внутреннего отражения (НПВО), были созданы относительно недавно. Этот тип светофильтров имеет ряд преимуществ по сравнению со светофильтрами, работающими на основе интерференции при нормальном падении излучения. К ним, в частности, относятся минимальное количество интерференционных слоев, входящих в состав светофильтров, широкие зоны подавления и возможность использования их в качестве поляризатора. Узкополосный светофильтр на основе НПВО, рассмотренный в работе [1], состоит из трех чередующихся диэлектрических слоев, изготовленных из материалов с низким и высоким показателями преломления, расположенных между средами с одинаковыми показателями преломления. Слои формируются на подложке, выполненной в виде треугольной призмы и изготовленной из оптического материала с высоким показателем преломления, один из острых углов которой больше предельного угла полного внутреннего отражения на границе раздела призма-слой. Граничащий с подложкой слой имеет низкий показатель преломления, средний слой имеет такой же показатель преломления, как у подложки, а третий слой с низким показателем преломления граничит с призмой, подобной призме-подложке. В работе [2] граничащие с призмами слои заменяются воздушными зазорами. Другой вариант узкополосного светофильтра на основе НПВО, рассмотренный в [3], отличается тем, что количество используемых интерференционных слоев увеличивается до 21.

При расчетах (идеальное условие) угол падения излучения на покрытие, из которого формируются узкополосные светофильтры на основе НПВО, должен быть равен некой постоянной величине $\alpha_{0}$. При измерении спектральных характеристик данных светофильтров в спектрофотометрах результаты часто намного хуже по сравнению с теоретическими расчетами. Возможно, главная причина данной проблемы состоит в расходимости падающего пучка излучения, используемого в спектрофотометрах, поскольку узкополосные светофильтры на основе НПВО работают при падении излучения под углом, к которому очень чувствительны их спектральные характеристики. Поэтому нетрудно показать, что используемые падающие пучки должны быть строго параллельными. На практике хорошо коллимированные световые пучки могут удовлетворять такому требованию. Лазерные пучки не являются строго параллельными [4-6], поэтому совпадение расчетных и экспериментальных кривых маловероятно. В настоящей работе рассматривается условие, определяющее допустимую расходимость падающего пучка при измерении спектральных характеристик узкополосных светофильтров на основе НПВО. Реальная расходимость лазерных пучков составляет несколько долей миллирадиан, т.е. несколько угловых минут [7-9].

Для повышения точности расчета характеристик данных светофильтров необходимо учитывать расходимость падающего пучка. При этом используемые пучки излучения падают на покрытие светофильтров не строго под углом $\alpha_{0}$, а в некотором интервале углов в пределе их расходимости, что, возможно, приводит к отклонению экспериментальных спектральных характеристик светофильтров от расчетных. Предположим, что падающие пучки расходятся в пределе малого угла $\Delta \theta$ и при этом угол падения излучения на покрытие отклоняется на малое значение $\Delta \alpha_{0}$ (рис. 1). В общем случае излучение падает на светофильтры из воздуха, показатель преломления которого равняется единице. Из рис. 1 нетрудно заметить, что $\Delta \alpha_{0}=\Delta \theta^{\prime}$, где $\Delta \theta^{\prime}-$ угол преломления излучения в первой призме светофильтров, соответствующий отклонению падающего пучка на угол $\Delta \theta$. Этот 


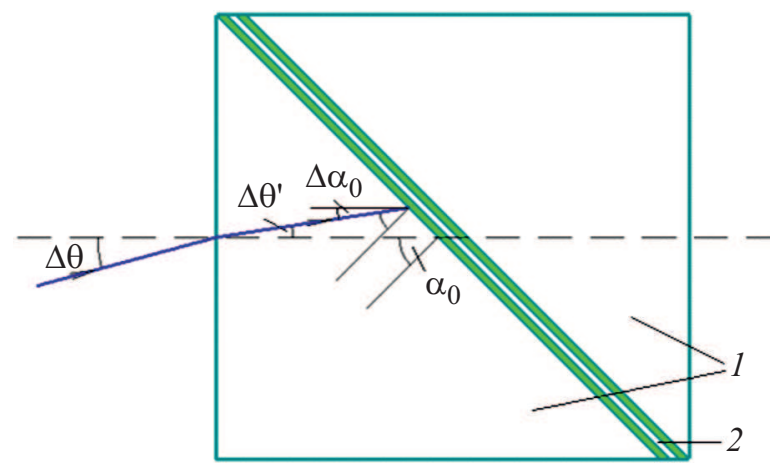

Рис. 1. Иллюстрация отклонения угла падения излучения на светофильтр. 1 - призмы, входящие в состав светофильтра, 2 - покрытие между призмами.

угол может быть определен из закона Снеллиуса

$$
\sin \Delta \theta^{\prime}=\frac{1}{n_{0}} \sin \Delta \theta
$$

где $n_{0}$ - показатель преломления материала, из которого изготовлены призмы светофильтров. Поскольку расходимость падающего пучка составляет малое значение, справедливы следующие приближения: $\sin \Delta \theta^{\prime}=\Delta \theta^{\prime}$ и $\sin \Delta \theta=\Delta \theta$. Следовательно,

$$
\Delta \alpha_{0}=\Delta \theta^{\prime}=\frac{\Delta \theta}{n_{0}} .
$$

Максимальное отклонение падающего пучка составляет величину $\pm \Delta \theta$. Согласно (2), отклонение угла падения света на фильтрующее покрытие между призмами составляет $\pm \Delta \theta / n_{0}$. Следовательно, световые лучи из пучка падают на фильтрующее покрытие под разными углами в диапазоне $\left[\alpha_{0}-\Delta \theta / n_{0} ; \alpha_{0}+\Delta \theta / n_{0}\right]$. Направление падения световых лучей может быть рассмотрено как случайная величина, что позволяет использовать гауссовское распределение (или нормальное распределение) для их описания $[10,11]$. Такое распределение характеризуется функцией плотности вероятности. Для величины угла падения световых лучей на рассматриваемое покрытие, согласно [12], функция плотности вероятности выражается как

$$
f(x)=\frac{1}{\sigma \sqrt{2 \pi}} \exp \left(-\frac{\left(x-\alpha_{0}\right)^{2}}{2 \sigma^{2}}\right),
$$

где $\sigma$ представляет собой среднее квадратичное отклонение угла падения света, $x-$ угол падения излучения на покрытие, математическим ожиданием является требуемый угол падения света $\alpha_{0}$. Для обеспечения падения на данное покрытие не менее $99.8 \%$ световых лучей под углом в диапазоне $\left[\alpha_{0}-\Delta \theta / n_{0} ; \alpha_{0}+\Delta \theta / n_{0}\right]$ среднее квадратичное отклонение угла падения излучения должно удовлетворять равенству $3 \sigma=\Delta \theta / n_{0}$. Отсюда получим $\sigma=\Delta \theta / 3 n_{0}$. Вероятность некоторого произвольного отклонения угла падения излучения попадет в интервал $a-b$, где $a<b$, составляет

$$
\rho=\int_{a}^{b} f(x) d x .
$$

Энергетический коэффициент пропускания рассматриваемых светофильтров может быть определен из следующего выражения:

$$
T(x, \lambda)=\frac{(1-R)^{2}}{1-2 R \cos 2 \varphi_{0}+R^{2}},
$$

где $\lambda$ - длина волны падающего излучения, $\varphi_{0}-$ фазовая толщина среднего слоя, $R$ - коэффициент отражения слоев, граничащих с призмами светофильтров. Фазовая толщина среднего слоя определяется выражением

$$
\varphi_{0}(x)=\frac{2 \pi n_{0} d_{0}}{\lambda} \cos x
$$

где $d_{0}-$ толщина среднего слоя. Коэффициент отражения слоев с низким показателем преломления описывается следующим выражением:

$$
R(x, \lambda)=\frac{\left(n_{0}^{2} n^{-1} \sin \varphi-n \sin \varphi\right)^{2}}{4 n_{0}^{2} \cos ^{2} \varphi+\left(n_{0}^{2} n^{-1} \sin \varphi+n \sin \varphi\right)^{2}},
$$

где $n-$ показатель преломления граничащих с призмами слоев, $\varphi-$ фазовая толщина данных слоев, которая определяется как

$$
\varphi(x)=\frac{2 \pi d}{\lambda} \sqrt{n^{2}-n_{0}^{2} \sin ^{2} x},
$$

где $d-$ толщина граничащих с призмами слоев.

С учетом гауссовского распределения падающего излучения выражение для определения энергетического коэффициента пропускания данного фильтра может быть переписано в виде

$$
T(\lambda)=\int_{\alpha_{0}-\Delta \theta / n_{0}}^{\alpha_{0}+\Delta \theta / n_{0}} T(x, \lambda) f(x) d x .
$$

Выражение (9) позволяет определить энергетический коэффициент пропускания узкополосных светофильтров на основе НПВО с учетом расходимости падающего пучка излучения в некотором угловом пределе $\pm \Delta \theta$; следовательно, оно позволяет определить предельное значение $\Delta \theta$, при котором максимум пропускания данных светофильтров еще наблюдается.

С учетом данных, изложенных в работе [1], одна из возможных конструкций узкополосных светофильтров на основе НПВО была реализована из следующих материалов: две одинаковые призмы, изготовленные из стекла российской марки К8, слои с низким показателем преломления из $\mathrm{MgF}_{2}$ и средний слой из $\mathrm{SiO}_{2}$. Для соединения призм был использован оптический клей 


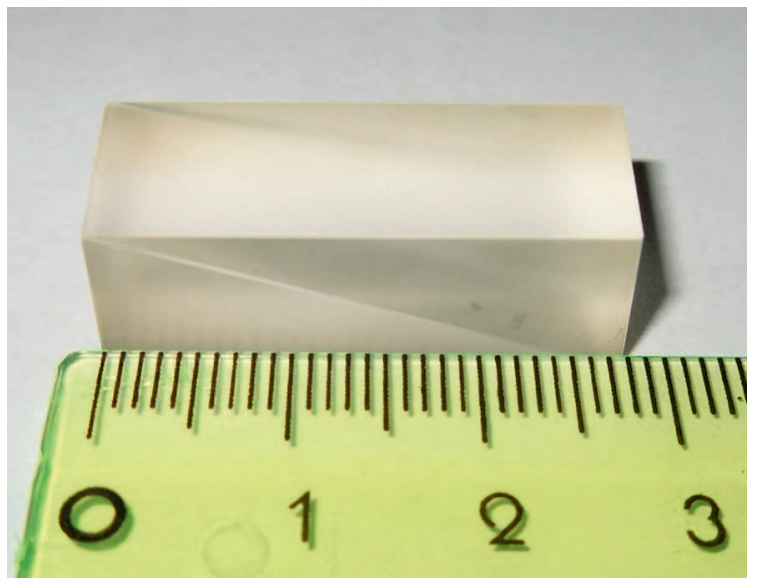

Рис. 2. Внешний вид светофильтра на основе НПВО с габаритными размерами $8 \times 8 \times 28 \mathrm{~mm}$.

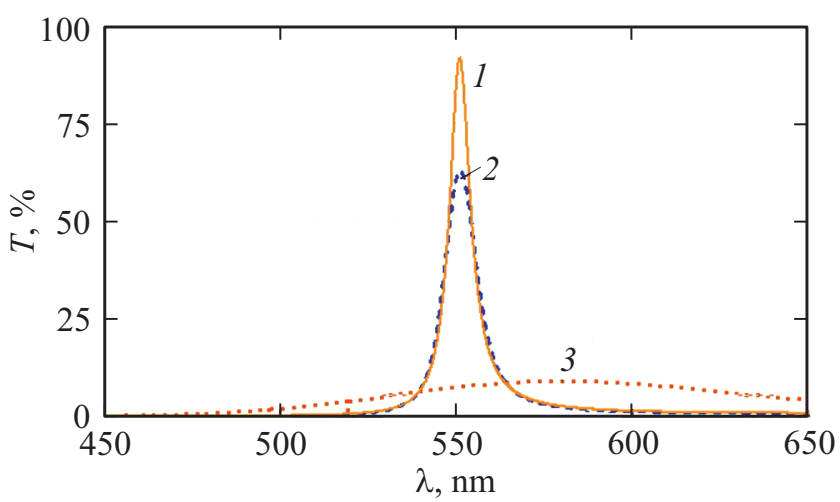

Рис. 3. Спектральные характеристики светофильтра на основе НПВО при расходимости падающего пучка излучения: $\Delta \theta=0(1), 5^{\prime}$ (2) и $90^{\prime}(3)$.

Норланд 61. Внешний вид данного светофильтра представлен на рис. 2.

При измерении спектральной характеристики этого светофильтра в спектрофотометрах, например в спектрофотометре ПЭ-5400УФ, максимум пропускания не обнаруживается (кривая 3 на рис. 3). Это обстоятельство может быть объяснено тем, что пучок излучения в указанном спектрофотометре не является параллельным пучком, угол его расходимости составляет $1.5^{\circ}$.

Анализ рис. 3 показывает, что расходимость падающего пучка сильно искажает спектральные характеристики узкополосного светофильтра, работа которого основана на явлении НПВО в интерференционных слоях. Для того чтобы наблюдать пропускание не менее $60 \%$ в максимуме в зоне прозрачности, данный светофильтр должен работать при расходимости падающего пучка излучения не больше 5 угловых минут.

Таким образом, для узкополосных светофильтров, работающих при наклонном падении излучения, небольшая расходимость падающего пучка может значительно искажать их спектральную характеристику. Полученные результаты позволяют установить допуск на расходимость падающего пучка излучения, использованного при работе или измерении спектральных характеристик данных светофильтров. Для рассматриваемой конструкции узкополосного светофильтра на основе явления НПВО в интерференционных слоях значение предельной расходимости падающего пучка излучения составляет 5 угловых минут.

\section{Финансирование работы}

Работа выполнена при поддержке Министерства образования и науки РФ в рамках госзадания (тема № 3.2506.2017/4.6).

\section{Список литературы}

[1] Nguyen V.B., Gubanova L.A. // J. Opt. Tech. 2016. V. 83. N 12. P. 734-737. DOI: 10.1364/JOT.83.000734

[2] Chesnokov V.V., Chesnokov D.V., Surneva A.S. // Optoelectron. Instr. Data Process. 2015. V. 51. N 2. P. 205 211. DOI: $10.3103 / \mathrm{S} 8756699015020156$

[3] Baumeister P.W. // Appl. Opt. 1967. V. 6. N 5. P. 897-905. DOI: 10.1364/AO.6.000897

[4] Жуков А.Е., Гордеев Н.Ю., Шерняков Ю.М., Паюсов А.С., Серин А.А., Кулагина М.М., Минтаиров С.А., Калюжный Н.А., Максимов М.В. // Письма в ЖТФ. 2018. Т. 44. B. 15. C. 46-51. DOI: 10.21883/PJTF.2018.15.46439.17345

[5] Ананьев Ю.А. Оптические резонаторы и лазерные пучки. М.: Наука, 1990. 264 с.

[6] Гаспарян П.Д., Стариков Ф.А., Старостин А.Н. // УФН. 1998. Т. 168. № 8. C. 843-876. DOI: $10.3367 /$ UFNr.0168199808b.0843

[7] Vidal E., Otaduy D., Gonzalez F., Saiz J.M., Moreno F. // Proc. of SPIE. 2017. V. 7428. P. $74280 \mathrm{C}$ (1-10). DOI: $10.1117 / 12.825287$

[8] Malacara D., Harris O. // Appl. Opt. 1970. V. 9. N 7. P. 1630 1633. DOI: $10.1364 / \mathrm{AO} .9 .001630$

[9] Lu Z.G., Li M.M., Zheng T., Wang L., Tan A.J. // Opt. Express. 2016. V. 24. N 14. P. 15854-15862. DOI: $10.1364 / \mathrm{OE} .24 .015854$

[10] Karimi E., Zito G., Piccirillo B., Marrucci L., Santamato E. // Opt. Lett. 2007. V. 32. N 21. P. 3053-3055. DOI: $10.1364 /$ OL.32.003053

[11] Дубровский В.Г. // Письма в ЖТФ. 2016. Т. 42. В. 13. С. 44 50.

[12] Krisnamoorthy $K$. Handbook of statistical distributions with applications. N.Y.: Chapman \& Hall/CRC, 2006. 344 p. 